\title{
LA ÉTICA MEDIO AMBIENTAL: PRINCIPIOS Y VALORES PARA UNA CIUDADANÍA RESPONSABLE EN LA SOCIEDAD GLOBAL
}

\author{
Juan Alberto Lecaros Urzúa ${ }^{1}$
}

Resumen: La ética medioambiental es una ética aplicada que reflexiona sobre los fundamentos de los deberes y responsabilidades del ser humano con la naturaleza, los seres vivos y las generaciones futuras. El objetivo de este artículo es evaluar la crisis socioecológica planetaria, bajo la guía de dos principios éticos axiales y un concepto ético-político derivado: primero, el principio de responsabilidad como cuidado del ser vulnerable (los seres humanos actuales y futuros y la restante vida planetaria); segundo, el principio de justicia ecológica en sus tres vertientes complementarias: la justicia global (las desigualdades socioeconómicas a nivel planetario), la justica intergeneracional (generaciones futuras) y la justicia interespecífica (principio de hospitalidad biosférica hacia los otros seres vivos); y el concepto ético-político de ciudadanía ecológica en una sociedad global.

Palabras clave: crisis socioecológica, ética medio ambiental, principio de responsabilidad, justicia global, ciudadanía ecológica

\section{Environmental ethics: principles and values for a responsible citizenship in global society}

\begin{abstract}
Environmental ethics is an applied ethics which reflects about the grounds for duties and responsibilities of humans towards nature, living beings and future generations. The aim of this paper is to evaluate the planetary socio-ecological crisis guided by two axial ethical principles and an ethical-political concept derived: first, from the principle of responsibility and of care for the vulnerable being (current and future human beings and all other life on planet); second, the principle of ecological justice in its three complementary aspects: global justice (socio-economic inequalities at the global level); both justice intergenerational (future generations) and interspecies (principle of biospherical hospitality towards other living beings); and the ethical-political concept of ecological citizenship in a global society.
\end{abstract}

Key words: socio-ecological crisis, environmental ethics, principle of responsibility, global justice, ecological citizenship

\section{A ética do meio ambiente: princípios e valores para uma cidadania responsável na sociedade global}

Resumo: A ética do meio ambiente é uma ética aplicada que reflete sobre os fundamentos dos deveres e responsabilidades do ser humano com a natureza, os seres vivos e as geraçóes futuras. O objetivo deste artigo é avaliar a crise socioecológica planetária, sob a orientaçâo de dois princípios éticos axiais e um conceito ético-político derivado: primeiro, o princípio da responsabilidade como cuidado do ser vulnerável (os seres humanos atuais e futuros e a demais vida planetária); segundo, o princípio da justiça ecológica em suas três vertentes complementares: a justicia global (as desigualdades socioeconômicas em nível planetário), a justiça intergeracional (geraçóes futuras) e a justiça interespecífica (princípio de hospitalidade biosférica para os outros seres vivos); e o conceito ético-político de cidadania ecológica em uma sociedade global.

Palavras-chave: crise socioecológica, ética do meio ambiental, princípio de responsabilidade, justiça global, cidadania ecológica

\footnotetext{
${ }^{1}$ Centro de Bioética, Facultad de Medicina, Universidad del Desarrollo, Chile Correspondencia: albertolecarosurzua@gmail.com
} 


\section{Introducción}

La primera vez que se comenzó a hablar de una ética orientada al cuidado y respeto del medio ambiente, indicando que el pensamiento moral debería ir más allá del ámbito de los intereses humanos para incluir los intereses de los seres naturales no humanos, fue en las conclusiones del libro de memorias del ingeniero forestal norteamericano, Aldo Leopold, "A Sand County Almanac" (1949), que la tituló: Land Ethic (Ética de la Tierra)(1). En los años setenta, en el ámbito académico anglosajón, se comienza utilizar la expresión "Environmental Ethics" para referirse a esta nueva área de la ética aplicada. Esta expresión se consolidó a partir de una conferencia de la Universidad de Georgia titulada "Filosofía y crisis medioambiental" (1971), en la que se hacía eco de una preocupación por estos temas ya presente por ese entonces en el debate social, a través de los primeros movimientos ecologistas de los años sesenta, y en el debate político-jurídico internacional. Recordemos que la primera Conferencia de Naciones Unidas sobre Medio Ambiente se celebró en Estocolmo en 1972 ("Conferencia de NN.UU sobre Medio Humano") y que ese mismo año se publicó el Informe del Club de Roma, "Los límites del crecimiento"(2).

A partir de entonces el concepto de environmental ethics adquirió carta de nacimiento y se definió como "el estudio ético de las interacciones humanas con y el impacto humano sobre el mundo natural y el sistema natural" (3), o bien, como "un nuevo campo de la ética filosófica preocupada por la descripción de los valores que posee el mundo natural no humano y por la prescripción de una respuesta ética apropiada para asegurar la preservación o restauración de estos valores"(4).

En 1972, con la conferencia del filósofo Arne Naess "The Shallow and the Deep, Long-Range Ecology Movement", publicada en Inquiry 16, 1973, se comenzó hacer la distinción entre ecología profunda (deep ecology) y ecología superficial (shallow ecology) y se introduce el término "ecofilosofía". Este último, según Naess, apunta a "hacer hincapié en una ponderación altamente crítica de las sociedades de crecimiento industrial desde el punto de vista ecológico"(5).
En 1975, con la publicación del libro "Liberación Animal", de Peter Singer, se inicia el debate dentro de la environmental ethics sobre los derechos de los animales y el bienestar animal (animal-welfarism), tanto desde la perspectiva utilitarista de la igual consideración de los intereses morales de los seres vivos sintientes (Singer)(6), como desde la perspectiva de los derechos de los animales con conciencia de fines (Regan)(7).

En el ámbito filosófico continental, dos de los grandes filósofos que abordaron esta dimensión de la ética y su fundamentación (Hans Jonas y K. O. Apel) no utilizaron el término "ética medioambiental" sino el de "ética de la responsabilidad". El primero habla de una "ética para la civilización tecnológica” —expresión que será el subtítulo de su celebérrima obra, "El principio de responsabilidad" (1979)(8)—_ y el segundo de una "ética de la responsabilidad en la era de la ciencia" (9) — título de una de sus primeras conferencias sobre el tema, dictada en 1984.

El debate filosófico en esta disciplina se ha centrado en tres grandes líneas: (i) el diagnóstico sobre las causas de la crisis socioecológica en un nivel planetario, en términos históricos, sociales, culturales, políticos, jurídicos y económicos; (ii) la consideración de los intereses morales de los seres humanos futuros o generaciones futuras, y (iii) la teoría del valor sobre la cual se sustentan las obligaciones ético-ecológicas, dividida en valores instrumentales, extrínsecos a la naturaleza y basados en los intereses humanos - que fundamentan los antropocentrismos éticos-, y en valores intrínsecos a la naturaleza o a los seres vivos que la integran, fundamento de los biocentrismos y ecocentrismos en ética medio ambiental.

El axioma clave para comprender la extensión del horizonte de consideración moral más allá de los intereses humanos actuales, esto es, el de las generaciones futuras y los seres vivos no humanos, se puede expresar diciendo que todo agente moral es paciente moral, pero no todo paciente moral es un agente moral. Por agente moral se entiende a los seres humanos con capacidad de asumir obligaciones y responsabilidades por sus acciones, y por paciente moral un ser ante el cual se tiene obligaciones y responsabilidades, debido a que sus intereses y capacidades merecen consideración mo- 
ral. Esta distinción significa que en el núcleo de la ética medio ambiental se abre la discusión sobre la existencia de deberes no recíprocos y asimétricos, vale decir, deberes que se tienen sin que exista un derecho correlativo. Sin embargo, el principio de la igual consideración de los intereses de los seres vivos no humanos no implica que se otorgue un mismo significado moral a los seres ante los cuales estamos obligados en una ética extendida hacia la naturaleza, pues se reconocen y establecen prioridades en caso de conflicto de intereses entre las entidades consideradas moralmente(10).

Desde los tiempos del padre fundador de la ética medioambiental, Aldo Leopold, ha estado presente en esta disciplina la visión de que la ética ha ido ampliando su horizonte de consideración moral. En efecto, durante buena parte de la historia de la humanidad el ámbito de consideración moral quedaba reducido a los miembros de una misma tribu, etnia o comunidad política, excluyéndose a los restantes seres humanos como extraños morales. Solo a partir del pensamiento ilustrado en el s. XVIII, se comienza a postular, con I. Kant, un criterio ético de universalidad, argumentando que las diferencias de raza, sexo, etnia o de otro tipo no constituyen diferencias éticamente razonables, y que todo individuo humano merece respeto por ser un fin en sí mismo, un ser con dignidad, no pudiendo ser tratado jamás como un mero medio para los fines de la voluntad de otros.

Hoy, sin embargo, dada la amplitud de los efectos de la acción humana en el tiempo y en el espacio, por el poder tecnológico, comenzamos a preguntarnos si este principio de universalidad es extensible incluso a los seres humanos futuros, los cuales pueden verse afectados en sus intereses por nuestras acciones presentes. Si la ética tiene por misión proteger al "otro", vulnerable y frágil, y aunque los individuos futuros no estén presente al mismo tiempo que nosotros, deberíamos considerar sus intereses morales, porque sus capacidades, vulnerabilidades y necesidades no deberían ser sustancialmente distintas de las nuestras(11).

Con todo, más allá del principio de universalidad de los intereses de los seres humanos actuales y futuros, el pensamiento ético, ya desde fines de la Ilustración, se preguntó si el criterio para considerar los intereses morales se limitaba solo a la capacidad de raciocinio propia de la especie hu- mana. Así, el padre del utilitarismo, J. Bentham, sostuvo que lo esencial en la moralidad no es pertenecer a una especie determinada, sino ser un individuo con capacidad de placer y sufrimiento. De tal modo que los animales sintientes tienen tanto interés en no sufrir como cualquier miembro de la especie humana, por lo tanto, merecen igual consideración moral que éstos. Es el razonamiento que ha seguido, por ejemplo, la ética del bienestar animal de Peter Singer.

Pero, dentro de la ética medio ambiental, otros filósofos se han preguntado si este es un criterio último para fijar el límite de la consideración moral de los seres naturales, ya que, sostienen, hay otros seres vivos que, sin ser sensibles, poseen igualmente un fin propio que buscan realizar y con los cuales los animales sintientes comparten capacidades e intereses, como la autoperpetuación metabólica, la respiración y la reproducción. Esta línea argumental es la propia de las posturas biocéntricas. Aunque hay bastantes matices entre ellas, pues unos postulan un igualitarismo biótico radical(12) y otros un biocentrismo moderado, que establece jerarquías de fines entre los distintos seres vivos(13).

Por último, otras corrientes dentro de la ética medioambiental han puesto el criterio de consideración moral más que en los individuos vivos en los sistemas naturales que estos forman, a saber, especies, ecosistemas y biosfera. Es la postura que adoptan los ecocentrismos. Aunque aquí también hay matices, pues unos privilegian a los sistemas vivos (comunidades bióticas y ecosistemas) por sobre los individuos(14), mientras que otros establecen una coordinación entre los intereses de los individuos vivos y las especies, considerando que éstas son el nivel adecuado de valoración y los sistemas vivos más complejos solo tienen un valor derivado de estas últimas(15).

Si bien la ética medioambiental, en sus distintas corrientes de fundamentación, ha puesto hoy sobre la mesa la necesidad ineludible de contemplar más allá de los intereses presentes de los seres humanos, los debates de esta disciplina resultan muchas veces escolásticos e infructuosos para enfrentar un cambio pragmático de la sociedad actual y su relación con la naturaleza, esto es, un cambio en el metabolismo socionatural. 
Por eso, consideramos que para desarrollar una ética medio ambiental es necesario equilibrar un antropocentrismo ético moderado con un biocentrismo. Esto quiere decir que la primera obligación ética ecológica es garantizar la supervivencia humana y la dignidad de la vida humana actual y futura, puesto que lo primero en verse afectado por la crisis socioecológica es el proyecto civilizatorio humano, con todos sus logros y riquezas culturales, científicas, éticas y políticas. Ello, por lo demás, teniendo en cuenta que la vida planetaria, pese a los impactos ambientales humanos, seguirá adelante en su proceso evolutivo.

Sin embargo, en la medida en que una vida humana digna en el presente y en el futuro es impensable sin la conservación y cuidado de la biosfera, es necesario precisar que el interés del hombre finalmente coincide con el resto de lo vivo, teniendo en cuenta además que el valor de la Tierra como biosfera significa que es el origen común de ambos y su morada (oikos) en el más sublime de los sentidos. De modo que podemos considerar ambos deberes como uno solo, bajo la idea del deber para con el futuro de la humanidad, sin caer por ello en un reduccionismo antropocentrista excluyente. Por el contrario, reducir el deber ético exclusivamente al hombre hoy en día significaría deteriorar el significado de una existencia humana digna en la Tierra. Este es el razonamiento que ha desarrollado el filósofo Hans Jonas bajo el principio de responsabilidad, como cuidado por el ser vulnerable, que comprende a las generaciones futuras y a la entera biosfera(8).

Una vez revisadas las distintas teorías de fundamentación en ética ecológica, se tiene la impresión de que ninguna de ellas por sí sola es suficiente para abordar la crisis socioecológica. A nuestro juicio, la crisis ecológica planetaria solo puede entenderse y abordarse como una crisis de ajuste metabólico entre la actual sociedad global y el medioambiente, en su doble vertiente: (i) la crisis entre el sistema social en su conjunto y el sistema biosférico; y, (ii) la crisis interna de la sociedad global causada por las desigualdades socioecológicas. Con el fin de compensar estos sesgos teóricos que se dan en la ética ecológica y elaborar una teoría de enfoque múltiple, proponemos algunos principios:
- El principio de responsabilidad como cuidado del ser vulnerable (los seres humanos actuales y futuros y la restante vida planetaria).

- El principio de justicia ecológica en sus tres vertientes: la justicia global (las desigualdades socioeconómicas a nivel planetario), la justica intergeneracional (generaciones futuras) y la justicia interespecífica (principio de hospitalidad biosférica hacia los otros seres vivos). Son principios que pueden entrar en conflicto y que debemos jerarquizar de acuerdo con ciertos principios estratégicos.

- Principios estratégicos: sustentabilidad, precaución y responsabilidad compartida, pero diferenciada y solidaria.

\section{Ciudadanía ecológica responsable}

La crisis socioecológica planetaria: la sociedad global del riesgo y las asimetrías de la globalización económica

Nuestra situación actual, como decía el biólogo Barry Commoner(16), es de un profundo desajuste entre la esfera que nos acoge (biosfera), sujeta a límites biofísicos y hoy saturada ecológicamente por el hombre, y la esfera humana y tecnológica (tecnosfera), compuesta por una población excesiva para los límites naturales y con un acelerado ritmo de producción y consumo, si bien el de unos pocos: los ricos globalizados de los países desarrollados y subdesarrollados. La envergadura de este desequilibrio no tiene precedentes en la historia y hace surgir la pregunta de cómo y por qué hemos llegado a este punto.

La gran transformación de la Tierra se inicia con la Revolución Industrial de fines del s. XVIII, cuando por primera vez se dejan de utilizar energías exosomáticas renovables (fuerza animal y energía solar directa e indirecta) y comienza el uso de energías fósiles no renovables, pasándose de una economía orgánica de flujos a una economía de stocks finitos de materias energéticas y no energéticas subterráneas. Pero, por esos tiempos, en un mundo vacío o no saturado en términos ecológicos(17), el capital natural no era una preocupación, pues existía en abundancia, por lo que obviamente el énfasis recaía en la productividad 
del capital humano y técnico. Hoy, en cambio, en un mundo lleno o saturado en términos ecológicos por una sociedad industrial planetaria que produce y consume por sobre los niveles de recursos naturales finitos disponibles y por sobre la capacidad de absorción de la biosfera de los desechos y contaminación generados, el capital natural debe ser nuestra primera preocupación. Por ello, es necesario ajustar nuestra tecnosfera a los límites que fija la biosfera, puesto que los procesos lineales de la primera, aunque innovadores, son ecológicamente inarmónicos o desajustados con la segunda, cuyos procesos son cíclicos, conservadores y autocoherentes(18).

En el declinar de la fase "fordista" del capitalismo, basado en el petróleo y la industria petroquímica (pesticidas, fertilizantes, plástico, etc.), entramos ahora a la Tercera Revolución Industrial, iniciada con la era de la energía atómica y que se despliega con la revolución de la ingeniería genética y la informática. En esta fase alcanzamos la capacidad de intervenir con la biotecnología en el proceso evolutivo, pudiendo transformar la estructura genética de plantas, animales y del ser humano mismo(19).

Hay dos características básicas del proceso de la sociedad industrial y tecnológica actual: la globalidad de sus impactos ambientales y la irreversibilidad de muchos de ellos (por ejemplo, la pérdida de la biodiversidad). Esto nos lleva a describir dos formas que toma la sociedad planetaria actual: la sociedad global del riesgo y la asimetría del proceso de la globalización económica y tecnológica.

Hemos llegado a un punto en la historia en que, por la magnitud de expansión de los efectos (población y escala de producción y consumo) y la calidad de penetración de la tecnología en las raíces de la naturaleza (tecnología no solo transformadora, sino también recreadora de lo natural), la sociedad actual se instala en una situación de riesgo contextual permanente como parte de sus procesos y actividades. El sociólogo U. Beck caracteriza a la actual civilización planetaria con cinco tesis: (i) los riesgos actuales causan daños sistemáticos y a menudo irreversibles que requieren una definición científica de los mismos en los contextos sociales; (ii) los riesgos generan nuevas desigualdades internacionales entre los países del tercer mundo y los industrializados, y dentro de estos últimos; (iii) la expansión de los riesgos aumenta la lógica productivista del capitalismo; (iv) el conocimiento científico de los riesgos adquiere un nuevo significado político, y (v) los riesgos afectan la salud y el medioambiente, pero también generan efectos secundarios sociales (hundimiento de mercados, aumento de costos, judicialización, etc.) (20).

En una sociedad que vive inmersa en actividades que tienen un fuerte potencial de generar daños graves e incluso irreversibles en el medio ambiente y la salud humana, la lógica con la cual operar no debería ser ya la de un enfoque de control o gestión de riesgos, sino un enfoque preventivo basado en el principio de precaución. Este principio estratégico, clave para la sociedad del riesgo actual, si bien discutido en su consistencia operativa, persigue las siguientes acciones y actitudes:

Actuar preventivamente frente a actividades riesgosas en un contexto de incertidumbre, antes incluso de disponer de una prueba científica plena sobre la peligrosidad de una actividad.

Una actitud de este tipo permite ganar un tiempo necesario para corregir los errores de actividades de riesgo ya emprendidas y para intensificar las investigaciones que permitan disipar la incertidumbre en nuevos proyectos.

El tiempo de precaución permite, además, intensificar la búsqueda de tecnologías o productos alternativos sin riesgo(21).

Otra de las características de la sociedad actual es el proceso de globalización, que lleva asociado dos fenómenos: (i) la contracción espacio-tiempo, como efecto de cambios económicos y tecnológicos, como el transporte a larga distancia, las telecomunicaciones, entre otros, y (ii), una tendencia a la extraterritorialidad del capital, a través de empresas transnacionales de gran envergadura; por ejemplo, las diez más grandes del mundo manejan el 70\% del comercio internacional, el 80\% de la tierra dedicada a cultivos de exportación, la mitad de la producción petrolera mundial y son responsables del $50 \%$ de la emisión de gases de efecto invernadero(22). Esta interconectividad y aumento de magnitudes y aceleración, sin em- 
bargo, tiene efectos éticos y políticos profundos, generando una globalización para unos pocos (países del Norte, 20\% de la población mundial, y los ricos de los países subdesarrollados) y una disposición de los países pobres que viven de sus materias primas exportadas, con localización de los daños ecológicos y una desigual explotación y distribución de los recursos naturales(23).

Los investigadores del Instituto Wuppertal sostienen que la globalización no es un proceso homogéneo, sino de dos caras: una, la de los países que han quedado excluidos de la misma (África y gran parte de Latinoamérica), la otra, la de los países que se han sumado a la economía global del crecimiento (Corea del Sur, Taiwán, China, India, etc.). Durante la etapa de la globalización, la distancia entre países pobres y ricos ha registrado un aumento constante y elevado de casi un 20\%(24). Esta desigualdad queda en evidencia mediante los "índices de huella ecológica", que determinan cuál es la demanda de recursos naturales de una determinada economía, expresada en términos de espacio(25). Si bien entre 1960 y 2000 la huella ecológica global creció en un $80 \%$, superándose la capacidad biológica del planeta (la superficie biológicamente productiva en aproximadamente un 20\%), la diferencia entre países es enorme, lo que evidencia que los países ricos del Norte viven a costa del espacio ecológico de los países del Sur. La media de huella ecológica de los países de rentas altas es de 5,6 ha por persona, con una biocapacidad de 3,5 ha; los países de rentas medias es de 1,9 ha, con una biocapacidad de 3,5 ha; y los países de rentas baja es 1,1 ha, con una biocapacidad de 1,1 ha(26).

En resumen, los países ricos, que constituyen el $20 \%$ de la población mundial, consumen el $80 \%$ de los recursos de todo el planeta (recursos energéticos de origen fósil, recursos minerales, uso de servicios ambientales, etc.). Esta apropiación desigual de recursos naturales por parte de los países ricos fuera de sus territorios, deja una carga medio ambiental en los países productores de materias primas de la que no se hacen cargo los primeros. Esto se muestra, por ejemplo, en el calentamiento climático, causado por el sobreconsumo energético del Norte, pero que afectará más gravemente a los países del Sur, que tienen claramente menos responsabilidad en él. Ello exige la aplicación del principio estratégico de responsabilidad compartida pero diferenciada, consagrado en la Declaración de Río (1992).

Sumado a la desigual distribución de los daños ecológicos, existe un desigual intercambio ecológico, debido a que las economías extractivas del primer mundo utilizan materias primas, la mayoría de ellas localizadas en los países del Sur, que dejan un desgaste no solo físico en su medio ambiente - por ejemplo, la extracción de minerales o maderas-, sino también social, por subvaloración del trabajo y de la salud de los pobres en el mundo, lo que exige internalizar esos costos en los $\operatorname{precios}(27)$.

Sin embargo, las consecuencias de un crecimiento económico desmedido están afectando también a los propios países que más se benefician de él. Comprobado está que, pasado cierto umbral de crecimiento económico (medido en términos de PNB), éste deja de contribuir al bienestar humano y se torna contraproducente debido a los dańos ecológicos y sociales asociados a este crecimiento(28). Así lo han mostrado índices corregidos del PNB que contemplan la calidad de vida. Por ejemplo, el Índice de Bienestar Económico Sostenible (IBES) de H. Daly nos muestra que en uno de los países más industrializados del mundo, como Estados Unidos, si bien entre 1950 y 1976 su IBES aumentó en un 43\%, a partir de ese último ańo este índice ha disminuido de forma constante hasta en un $12 \%$ hasta 1988 , pese a que el PNB por persona en ese mismo periodo seguía creciendo(29). Lo mismo ha demostrado el Índice Ajustado del PNB de Paul Ekins, que deduce costos sociales y ambientales e incorpora índices de salud, sociales y la economía familiar como un valor económico(30). Estos índices para valorar adecuadamente el progreso humano en términos cualitativos requieren sin duda un fundamento antropológico y filosófico sobre el sentido de la buena vida humana. Estudios claves en esta línea han sido los de Martha Nussbaum ("Las mujeres y el desarrollo humano", 2002) y los de Doyal \& Gough ("Teoría de las necesidades humanas", 1994). 
La justicia ecológica: justicia global, justicia interespecífica y justicia intergeneracional

Hoy es necesario introducir un concepto redefinido de progreso que vaya más allá de lo cuantitativo y esté orientado hacia la sustentabilidad ecológica, lo que implica producir de forma más eficiente (hacer más con menos energía y materias primas) y que los sistemas socioeconómicos respeten los límites de la biosfera. El Instituto Wuppertal ha definido la sostenibilidad en los siguientes términos: "La dimensión física de la sustentabilidad se refiere a dejar intacta a lo largo del tiempo la estabilidad de los procesos evolutivos internos de la ecósfera, una estructura dinámica y autoorganizativa. Un sistema económico es ecológicamente sostenible solo en tanto el empleo de recursos para generar bienestar se limite de forma permanente a un tamaño y una calidad que no sobreexplote las fuentes, ni sobrecargue los sumideros que proporciona la ecósfera”.

Si tomamos en cuenta que ya estamos superando los límites biofísicos del planeta, pero con una distribución muy desigual de las ventajas y las pérdidas, tanto entre los habitantes actuales del planeta como en relación con las generaciones futuras y también con el espacio ambiental que dejamos disponible para los otros seres vivos y sus procesos ecológicos, esto tiene implicaciones en el sentido que damos al concepto de "justicia". Por consiguiente, tres grandes líneas de trabajo de una justicia ecológica planetaria es necesario hoy asumir: la justicia global, la justicia interespecifica y la justicia intergeneracional.

Siguiendo a Sachs \& Santarius, la justicia global debe ser entendida como una ética transnacional basada en el reconocimiento de todos los individuos como miembros de pleno derecho en la comunidad (derechos humanos básicos de subsistencia y distribución justa de los recursos), garantizando estos derechos de supervivencia por sobre el bienestar de otros, mediante un comercio justo y la compensación de daños ecológicos bajo el principio de responsabilidades comunes pero diferenciadas(24).

La justicia interespecifica tiene que ver con la idea de hospitalidad biosférica, que nos recuerda que somos una especie dependiente de los procesos de la ecósfera que desarrollan otros seres vivos, y que no debemos apropiarnos de modo desigual del espacio ambiental que compartimos.

\section{Estructura modificada de la acción humana en la sociedad tecnológica según Hans Jonas y Günther Anders}

(1) Abismo entre la acción individual y sus efectos: en una sociedad mecanizada y con una fuerte división del trabajo, desde el trabajador más básico hasta el inventor más genial carecen de conciencia del producto que elaboran y los efectos de sus actividades, aunque este efecto sea la aniquilación de la especie humana.

(2) Efectos ambivalentes de la tecnología: por un lado, la tecnología acrecienta enormemente nuestra calidad de vida, pero, por otro, lo hace a un costo muy alto en dańos ecológicos y sociales; llegados a un punto de crecimiento económico, éste no genera bienestar o calidad de vida.

(3) Tendencia acumulativa de los efectos de la acción tecnológica: disminuye la posibilidad de una buena vida para las generaciones futuras y puede generar efectos irreversibles en el medio ambiente.

(4) Enorme extensión espacial y temporal de la acción: las acciones en un lugar pueden repercutir en el planeta entero (por ejemplo, la contaminación por gases de efecto invernadero) y en extensiones de tiempo que van más allá de las generaciones presentes.

(5) Automatismo de la aplicación de los descubrimientos tecnocientificos: una vez entrado en el circuito social, un nuevo avance tecnológico no desaparece sino hasta que un avance superior lo reemplace y, además, con una tendencia a una utilización masiva del mismo en una sociedad del consumo.

(6) Nuevos objetos de consideración moral: el mayor alcance temporal y espacial de la acción introduce nuevos objetos éticos, tales como la entera biosfera y las generaciones futuras.

(7) La concentración del poder político, económico y financiero: una sociedad globalizada deja en manos de unos pocos decisiones que afectan a muchos (millones de personas).

(8) Orientación colectiva de la ética: ahora la ética no solo se orienta a las conductas individuales sino al comportamiento de la humanidad entera frente a sus desafíos planetarios de orden ecológico y social. 
Por último, la justicia intergeneracional tiene que ver con el deber no recíproco de responsabilidad por las generaciones futuras, que se articula en tres principios derivados: principio de conservación de opciones, principio de conservación de la calidad del planeta y principio de conservación de acceso al legado de las generaciones pasadas(31).

El Informe Brundtland, "Nuestro futuro común" (1987), definía precisamente el concepto de "desarrollo sostenible" como aquel que satisface las necesidades del presente sin comprometer la capacidad de las generaciones futuras para satisfacer sus propias necesidades. Sin embargo, este concepto se ha interpretado de muchas formas en las últimas décadas. Algunos apuestan por un crecimiento sostenible, ambientalmente consciente, sin limitar el crecimiento económico, incorporando más y mejor tecnología para un desarrollo ecoeficiente. Otros consideran, en cambio, que la estrategia anterior implica un riesgo (en la conservación de recursos y disminución del impacto ambiental global) que se traduce en que el ahorro que se gana en ecoeficiencia se pierde por mayores posibilidades de sobreconsumo (paradoja de Jevons o efecto de rebote). Por esto, se propone que una sustentabilidad ecológica de los sistemas socioeconómicos debe orientarse primero a la frugalidad o a la suficiencia en el consumo de bienes, esto es, disminuir el consumo de recursos a través de menos demanda de bienes por la vía de la virtud ciudadana de la autocontención, en especial la de los ciudadanos globalizados(32).

El principio de responsabilidad como cuidado del ser vulnerable: hacia una ciudadanía ecológica

A nuestro modo de ver, en términos del fundamento ético de la idea de sustentabilidad, debe introducirse el principio de responsabilidad como cuidado del ser vulnerable, que implica para su conservación principios claves para el desarrollo sostenible, como son el principio de precaución, el principio de solidaridad (entre los seres humanos presentes y entre éstos y las generaciones futuras), el principio de autocontención (valores de suficiencia, moderación y frugalidad) y el principio de responsabilidad ciudadana global, que fundamenta el concepto de ciudadanía ecológica.

En el discurso ético, el concepto de responsabilidad es de aparición tardía. Las primeras éticas de la responsabilidad se comienzan a articular a partir de la segunda mitad del s. XX (Lévinas, Arendt, Jonas y Apel). El sujeto contemporáneo se encuentra hoy inserto en una amplia red de figuras de la responsabilidad, diversas y heterogéneas, que se mueven desde el polo subjetivo al polo institucional y colectivo, lo que obliga a repensar este concepto más allá del paradigma

\begin{tabular}{|l|l|l|}
\hline \multicolumn{1}{|c|}{ Características } & $\begin{array}{l}\text { Responsabilidad retrospectiva } \\
\text { (ex-ante) }\end{array}$ & \multicolumn{1}{|c|}{$\begin{array}{c}\text { Responsabilidad prospectiva } \\
\text { (ex-post) }\end{array}$} \\
\hline $\begin{array}{l}\text { Naturaleza del objeto de } \\
\text { responsabilidad }\end{array}$ & $\begin{array}{l}\text { Responsabilidad por los actos u u } \\
\text { omisiones pasadas y sus resultados, } \\
\text { sobre un hecho claramente } \\
\text { definido. }\end{array}$ & $\begin{array}{l}\text { Responsabilidad por hechos } \\
\text { futuros, sin determinación precisa, } \\
\text { evitando un estado de cosas dañino } \\
\text { en el mundo. }\end{array}$ \\
\hline Deberes de responsabilidad & $\begin{array}{l}\text { Deberes simples, relativos a a } \\
\text { hacer o no hacer algo en una } \\
\text { ocasión particular, y en caso de } \\
\text { incumplimiento, deber de reparar } \\
\text { daños. }\end{array}$ & $\begin{array}{l}\text { Deberes de cuidado, complejos } \\
\text { y amplios, con una esfera de } \\
\text { discrecionalidad para el agente. }\end{array}$ \\
\hline $\begin{array}{l}\text { Figura de referencia de la } \\
\text { responsabilidad (acciones) }\end{array}$ & $\begin{array}{l}\text { Acciones positivas u omisiones, } \\
\text { intervenciones que causan un daño } \\
\text { y que debe ser reparado }\end{array}$ & $\begin{array}{l}\text { Acciones por omisión, lo que se } \\
\text { deja de hacer por el cuidado del } \\
\text { objeto de responsabilidad. }\end{array}$ \\
\hline Fundamento axiológico & $\begin{array}{l}\text { Disvalor por el daño de la acción u u } \\
\text { omisión y compensación de daño } \\
\text { como valor. }\end{array}$ & $\begin{array}{l}\text { El valor del objeto de } \\
\text { responsabilidad de cuidado, el bien } \\
\text { propio de éste. }\end{array}$ \\
\hline Quién es responsable & $\begin{array}{l}\text { El agente individual en sentido } \\
\text { moral y/o legal. }\end{array}$ & La colectividad, la sociedad entera. \\
\hline
\end{tabular}


formal jurídico-político. Hoy este concepto toma fuerza, no como responsabilidad retrospectiva por las consecuencias o efectos de nuestras acciones pasadas (responsabilidad de), sino como responsabilidad prospectiva, esto es, una responsabilidad por el cuidado y protección de seres vulnerables (generaciones futuras y otros seres vivos), que pueden verse afectados por las consecuencias a largo plazo de nuestras acciones y el poder colectivo característico de las sociedades técnico-industriales (responsabilidad por, que implica deberes asimétricos y no recíprocos de cuidado).

Más allá de los debates sobre la responsabilidad colectiva en sentido legal y moral, que no es tema a puntualizar ahora, sintetizamos los supuestos mínimos de una responsabilidad moral ampliada para la sociedad global actual. Si tomamos en cuenta que este tipo de responsabilidad se caracteriza por ser colectiva y orientada al futuro (prospectiva), los supuestos mínimos de ella son: (i) quién es responsable: la humanidad actual en su totalidad, comprendiendo los individuos, empresas u organizaciones intermedias, Estados, organismos internacionales; (ii) de qué somos responsables: de los efectos de largo alcance en el espacio y el tiempo de las acciones emanadas del poder industrial y científico-tecnológico global, ante la vulnerabilidad y fragilidad de la humanidad actual y futura y la vulnerabilidad de la biosfera; (iii) ante quién somos responsables: una ética orientada al futuro implica deberes de cuidado por la solidaridad entre humanidad y biosfera, lo que significa dar un giro no antropocéntrico en relación con las éticas del pasado, basadas tanto en la reciprocidad entre deberes y derechos como en éticas del aquí y ahora, y (iv) en nombre de qué somos responsables: por la dignidad de la vida humana actual y futura, que no es separable de los límites ecológicos de la biosfera y los seres que la integran.

Finalizamos este artículo con las virtudes que emanan del principio de responsabilidad, como cuidado del ser vulnerable y su relación con el concepto emergente en el debate de la teoría política actual de ciudadanía ecológica, caracterizado por deberes no recíprocos y por las virtudes del cuidado y la compasión.

Proponemos un conjunto de valores para fundar la virtud de la autolimitación del ciudadano res- ponsable de la sociedad global, divididos en valores del pasado renovados para el mańana y valores necesarios para el futuro.

Entre los primeros, proponemos los valores de la suficiencia, autocontención y moderación. Por suficiencia, siguiendo a Manfred Linz, entendemos el valor que permite aumentar el bienestar humano, la calidad de vida y la autonomía. Teniendo en cuenta que el aumento en bienes materiales, una vez alcanzado un cierto umbral, suele ir en detrimento del bienestar relacionado con la riqueza en tiempo y la riqueza relacional, es necesario postular la suficiencia en el consumo como una forma de aumentar la calidad de vida y la autonomía, y contribuir así al primer paso necesario para una sociedad sustentable. La autocontención es un valor orientado a esta misma virtud de autolimitación(32). Siguiendo el análisis de J. Sempere -quien pone énfasis en la distinción entre lo necesario y lo superfluo, que en una sociedad del consumo cada vez se borra más-, para alcanzar una sociedad sostenible no basta solo con mayor ecoeficiencia en la producción, sino también cambiar los deseos y motivaciones que están detrás de la satisfacción de las necesidades(33). Por último, dentro de esta virtud de la autolimitación, Hans Jonas argumenta que el valor de la moderación, que hoy en día se exige para las sociedades contemporáneas, no tiene que ver estrictamente con la virtud clásica de la continencia, porque ahora es necesario un valor colectivo de la moderación de orden ético-político, que va más allá de un proyecto ético individual(34).

Dentro de los nuevos valores - antes inexistentes en las sociedades y ahora necesarios para enfrentar la crisis socioecológica actual y futura-, siguiendo a Hans Jonas y Günter Anders proponemos los siguientes, como complemento de la virtud de la autolimitación: 1) el valor del saber predictivo, mediante una disciplina seria de futurología como mecanismo necesario de control del poder tecnocientífico y de una ciencia planificada democráticamente; 2) el valor del temor ante la posible desfiguración del sentido de la vida humana (por ejemplo, a través de proyectos de recreación genética); 3) el valor de la precaución ante los riesgos de las actividades tecnocientíficas; 4) el valor de la modestia y humildad ante el poder de los avances de la tecnociencia; 5) el valor de la 
moderación ante sus amenazas; 6) el valor de la imaginación moral anticipativa frente a la "vergüenza prometeica" (por la humillante calidad de las cosas hechas por el ser humano)(35).

Sostenemos, además, que el principio de responsabilidad como deber de cuidado se articula por medio de una teoría de deberes no recíprocos y asimétricos, en cuanto sus objetos de cuidado carecen de la posibilidad de exigir derechos, puesto que estamos hablando del cuidado por seres humanos que aún no existen (generaciones futuras) y del cuidado de seres vivos no humanos. A partir de aquí introducimos el concepto de "ciudadanía ecológica", una de cuyas características son los deberes no recíprocos y las virtudes del cuidado y la compasión(36).

Valencia Sáiz y otros plantean que, más allá de los distintos modelos de sociedades sostenibles, éstas no pueden existir sin ciudadanos ecológicos. Toman este concepto emergente como una categoría abierta, aún en construcción, que se puede modelar a través de tres tipos de disposición ciudadana hacia el medioambiente: (i) adhesión moral (el ciudadano hace más que dice); (ii) cooperación voluntaria (conductas sostenibles responsables en el ámbito doméstico y privado) y (iii) participación activa (compromiso con la causa medio ambiental). Los autores resumen el debate actual del concepto emergente de ciudadanía ecológica diferenciándolo del concepto tradicional de ciudadanía en tres aspectos: (i) se trata de una noción basada no tanto en derechos como en obligaciones; (ii) en el ámbito de su ejercicio es tan importante la esfera de lo privado como la de lo público, y (iii) se dirige a un sujeto que va más allá del Estado-nación, siendo por ello una suerte de ciudadanía global(37).

El estudioso que más ha trabajado este concepto es Andrew Dobson, en su libro "Ciudadanía y medio ambiente" (2003). Este investigador ha planteado la "ciudadanía ecológica” como un concepto desestabilizador de las ciudadanías tradicionales, a saber la ciudadanía liberal y la republicana.

Para Dobson, la ciudadanía ecológica apunta más hacia deberes y responsabilidades que a derechos, e implicaría las virtudes del cuidado y compasión hacia los desconocidos y distantes, tanto en el tiempo como en el espacio (humanos y seres vivos no humanos). Este concepto considera que, en la medida en que los actos privados tienen implicaciones públicas, ya no es válida la distinción estricta entre lo público y lo privado. Por último, la ciudadanía ecológica supera el concepto territorial de las ciudadanías tradicionales ligadas al espacio político definido, entendiéndola entonces como una "ciudadanía de la Tierra", que supera el concepto de ciudadanía global o cosmopolita. En este sentido, es una especificación de una ciudadanía postcosmopolita(36).

\section{Conclusiones}

A partir de la descripción de la crisis socioecológica actual, mostramos la necesidad de seis transformaciones claves de una sociedad futura:

Pasar de una visión antropocéntrica del mundo que comprende solo los intereses y valores humanos a una visión solidaria entre el mundo natural y el mundo humano, que comprende los intereses y valores del resto de los seres vivos que comparten la biosfera con nosotros, lo que significa orientarse hacia una solidaridad antropocósmica y una justicia interespecífica.

Pasar de una sociedad dividida y territorialista (Estados-nación), aunada por una globalización económica y financiera asimétrica e injusta, a una sociedad no territorialista, que aspira a una sociedad global aunada en una conciencia planetaria que lucha por la igualdad y por la justicia global.

\begin{tabular}{|l|l|l|}
\hline Ciudadanía liberal & Ciudadanía republicana & Ciudadanía postcosmopolita \\
\hline $\begin{array}{l}\text { Derechos/Garantías } \\
\text { (contractual) }\end{array}$ & $\begin{array}{l}\text { Deberes/Responsabilidades } \\
\text { (contractual) }\end{array}$ & $\begin{array}{l}\text { Deberes/Responsabilidades } \\
\text { (no contractual) }\end{array}$ \\
\hline Esfera pública & Esfera pública & Esfera pública y privada \\
\hline Sin virtudes & Virtud "masculina" & Virtud "femenina" \\
\hline Territorial (discriminatorio) & Territorial (discriminatorio) & No territorial (no discriminatorio) \\
\hline
\end{tabular}


Pasar de una sociedad que solo comprende los intereses presentes a una sociedad planetaria que comprende los intereses de los seres humanos futuros, esto es, orientada hacia una justicia intergeneracional basada en el principio de responsabilidad por las generaciones futuras.

Pasar de una economía productivista, desarraigada de la Tierra, abstracta e inmaterialista —en cuanto separada de la biosfera- y materialista - en cuanto abusa de los recursos naturales mediante ritmos de producción y consumo desenfrenados-, a una economía que se inserta como un subsistema dentro del ecosistema físico, global y finito que es la biosfera, lo que significa pasar de una economía capitalista y productivista a una economía ecológica.

Pasar de sociedades insostenibles, depredadoras del medio y profundamente desiguales en lo social, a sociedades ecológicamente sostenibles más justas e igualitarias.

Pasar de una ciudadanía global para unos pocos a una ciudadanía ecológica, de la Tierra, consciente y activa desde su lugar de compartir una única Tierra para una humanidad actual y futura.
En relación con la justicia ecológica, se sostiene que solo es abordable a través de tres líneas de acción y conceptos complementarios: la justicia interespecífica, la justicia intergeneracional y la justicia global.

Proponemos que la filosofía de la sustentabilidad se base en el principio de responsabilidad como deber de cuidado por el ser vulnerable.

La teoría de la responsabilidad, en tanto teoría de deberes no recíprocos y asimétricos, se considera fundamento de una teoría contractualista de los derechos y deberes recíprocos.

Los límites encontrados al concepto emergente de ciudadanía ecológica, en virtud de estar basado en una ética del cuidado y el problema de la universalización de la misma en un contexto de pluralismo moral, pueden ser superados por la asunción de la teoría de los deberes no recíprocos de la responsabilidad, en tanto ésta se declina como virtud de cuidado y como deber de justicia, saliendo así al paso del problema de subordinar virtudes ciudadanas ecológicas (cuidado y compasión) al principio de justicia global.

\section{Referencias}

1. Leopold A. A Sand County Almanac and Sketches Here and There. Oxford: Oxford University Press, 1949.

2. Meadows D, et al. Los límites del crecimiento. México: Fondo de Cultura Económica; 1972.

3. Attfield R. Environmental Ethics. An Overview for the Twenty-First Century. Oxford: Blackwell; 2003.

4. Light A, Rolston III H, (eds.) Environmental Ethics. An Anthology. Oxford: Blackwell; 2006.

5. Naess A. Ecology, community and lifestyle. Outline of an Ecosophy. Cambridge: Cambridge University Press; 1989.

6. Singer P. Liberación Animal. Madrid: Trotta; 1999.

7. Regan T. Animal Rights. Berkeley: University of California Press; 1983.

8. Jonas H. El principio de responsabilidad. Ensayo de una ética para la civilización tecnológica. Barcelona: Herder; 1995.

9. Apel K-O. Una ética de la responsabilidad en la era de la ciencia. Buenos Aires: Almagesto; 1992.

10. Goodpaster K. On Being Morally Considerable. Journal of Philosophy 1978; 75(6): 308-325.

11. Attfield R. El ámbito de la moralidad. En: García Gómez-Hera JM, (coord.) Etica del medio ambiente. Problema, perspectiva, historia. Madrid: Tecnos; 1997.

12. Taylor PW. Respect for Nature. A Theory of Environmental Ethics. New Jersey: Princeton University Press; 1986.

13. Attfield R. A Theory of Value and Obligation. London: Routledge; 1995.

14. Callicott JB. In Defense of the Land Ethic. New York: Suny Press; 1989.

15. Rolston III H. Environmental Ethics. Duties and Values in The Natural World. Philadelphia: Temple University Press; 1988.

16. Commoner B. El círculo que se cierra. Barcelona: Plaza \& Janés; 1978.

17. Daly H. De la economía del mundo vacío a la economía del mundo lleno. En: Goodland R, et al. Medio ambiente y desarrollo sostenible. Más allá del informe Brundtland. Madrid: Trotta; 1997: 37-50. 
La ética medio ambiental - Juan Alberto Lecaros Urzúa

18. Commoner B. En paz con el planeta. Barcelona: Crítica; 1992.

19. Rifkin J. El siglo de la biotecnología. Barcelona: Crítica; 1999.

20. Beck U. La sociedad del riesgo. Barcelona: Paidós; 1998.

21. Riechmann J, Tickner J, (coords.) El principio de precaución en medio ambiente y salud pública: de las definiciones a la práctica. Barcelona: Icaria; 2002.

22. George S. Otro mundo es posible si... Barcelona: Icaria; 2004.

23. Shiva V. The Greening of Global Reach. En Dalby S, Routledge P, Tuathail, G (eds.) The Geopolitics Reader. Londres: Routledge; 1998.

24. Sachs W, Santarius T, (dirs.) Un futuro justo. Recursos limitados y justicia global. Barcelona: Icaria; 2007.

25. Wackernagel M, Rees W. Nuestra huella ecológica. Reduciendo el impacto humano sobre la tierra. Santiago de Chile: Lom Ediciones; 2001.

26. WWF. Living Planet Report; 2012.

27. Martínez Alier J. La economía ecológica como ecología humana. Madrid: Fundación César Manrique; 1998.

28. Max-Neef M. El desarrollo a escala humana. Barcelona: Icaria; 1994.

29. Daly H, Cobb J. Para el bien común. Reorientado la economía hacia la comunidad, el ambiente y un futuro sostenible. México DF: Fondo de Cultura Económica; 1993.

30. Ekins P. The Living Economy: A New Economics in the Making. London: Routledge and Kegan Paul; 1986.

31. Brown Weiss E. Un mundo justo para las futuras generaciones. Madrid: Mundi-Prensa/United Nations University Press; 1999.

32. Linz M, et al. Vivir (bien) con menos. Barcelona: Icaria; 2007.

33. Sempere J. Mejor con menos. Necesidades, explosión consumista y crisis ecológica. Barcelona: Noema; 2009.

34. Jonas H. Técnica, medicina y ética. Barcelona: Paidós; 1997.

35. Anders G. Filosofía de la situación. Antología. Madrid: Los libros de la catarata; 2007.

36. Dobson A. Ciudadanía y medio ambiente. Barcelona: Proteus; 2010.

37. Valencia Sáiz A, Arias Maldonado M, Vásquez García R. Ciudadanía y conciencia medio ambiental en España. Colección Opinión y actitudes, 67. Madrid: CIS; 2010.

Recibido: 27 de agosto de 2103

Aceptado: 23 de septiembre de 2013 